\title{
Community Treatment Orders (CTO's): a clinico-ethical perspective from Melbourne, Australia Gunvant Patel 1,2
}

\author{
Address: ${ }^{1}$ Forensicare (Victorian Institute of Forensic Mental Health), 200 Sydney Road, Brunswick 3056, Australia and ${ }^{2}$ St Vincents Hospital \\ Department of Psychiatry, Nicholson St, Fitzroy 3065, Australia \\ from WPA Thematic Conference. Coercive Treatment in Psychiatry: A Comprehensive Review \\ Dresden, Germany. 6-8 June 2007 \\ Published: 19 December 2007
}

BMC Psychiatry 2007, 7(SuppI I):S67 doi:I0.II86/I47I-244X-7-SI-S67

This abstract is available from: http://www.biomedcentral.com/I47I-244X/7/SI/S67

(c) 2007 Patel; licensee BioMed Central Ltd.

\section{Background}

To highlight the clinical and ethical impact on psychiatric care that has occurred since the introduction of involuntary community treatment via CTO's.

\section{Methods}

To present the author's experience of working in public psychiatry with CTO's since their introduction two decades ago. Reference to the limited research conducted will be made.

\section{Results}

CTO's have had a significant detrimental effect in reshaping services and quality of care without reducing levels of coercion. Research on their benefits is lacking despite an extended period of use.

\section{Conclusion}

The state of Victoria has been at the forefront of the move away from institutional to community based mental health practice. CTO's have been pivotal to this community focused model of service delivery. CTO's were readily adopted in Victoria twenty years ago with little extensive debate, and to date, there has been little open discussion about their actual value. This failure to examine their efficacy is due to a variety of reasons, which are outlined in the presentation. In the main, though, service managers and budget holders have been blinded to clinical and ethical issues that CTO's bring up because they assist services to manage the pressure on resources while, at the same time, they create an illusion of less restrictive care. This presentation highlights the various ways that clinical care has become cruder and less humane since the introduction of CTO's. These would seem to outweigh any benefits that are noted in specific examples and in the limited studies available. 